\title{
Setting Health-Care Priorities. What ETHical Theories Tell Us. A Response to My Critics
}

\author{
- Torbjörn Tännsjö -
}

\begin{abstract}
The article provides answers to comments in this journal on my recent book, Setting HealthCare Priorities. What Ethical Theories Tell Us (Oxford University Press, 2019). Did I address all of the relevant theories? Yes, I did. Was my argument underdeveloped in any respects? Yes, at least in one as I should perhaps have discussed contractual ethical thinking more carefully. I do so in this response. Moreover, the critical comments raised have helped me to clarify my argument in many ways, for which I thank my critics.
\end{abstract}

Keywords:

Published online: 30 June 2021

\section{Introduction}

My book discusses how to allocate scarce recourses for health-care purposes. The point of departure is the idea that we all bear a joint global responsibility for the provision of health-care. It is taken for granted, furthermore, that global needs will increase when we begin to sense the effects of global warming. The book was written just before the Covid19-pandemic and the events of the last 15 months have served to remind us of what we should expect in the future. Therefore there is no way that we can avoid hard choices when health-care resources should be distributed all across the world, irrespective of whether this takes place in the form of a cooperative scheme between independent nation states or in a global political order. The subject is treated in a philosophical and detached manner. The idea is to uncover the implications which stem from fundamental moral theories which inform us how to redirect resources for health-care needs in a systematic manner, and to provide moral explanations with reference to these theories as to why we ought to make the shifts I advocate.

The book presents three broad themes. First of all, I delineate what I consider to be the most plausible theories about how to distribute scarce resources. I speak of them as utilitarianism (with a possible modification with reference to prioritarianism), the maximin/leximin theory, and egalitarianism. I explain in detail what these theories

Torbjörn Tännsjö

Department of Philosophy

Stockholm University

10691 Stockholm, Sweden

e-mail: torbjorn.tannso@philosophy.su.se 
amount to and how they compare to one another in the abstract, i.e. in the philosophical laboratory where we perform thought experiments. I even try out their implications in population ethics. They each come with a typical rationale. At most, of course, one of them can be true yet each of them is 'defensible' or 'justifiable', even if it cannot have escaped the attention of any of my readers where my own personal sympathies lie, i.e. with total hedonistic utilitarianism. And since they are all defensible and justifiable it is of importance to find out about their implications.

Secondly, I claim that all the (plausible) theories about distributive justice that I discuss converge in an overlapping consensus. I speak of this as 'convergence'. They yield roughly the same kind of recommendations as to how medical resources should be redirected: from marginal life extension to attempts to establish and sustain mental health.

Thirdly, I claim that as a matter of fact, we will not abide by the converging radical implications of the theories, not even if we were, theoretically speaking, to accept any one of them. I claim that this has to do with our human irrationality. I speak of this as 'futility', explained by irrationality.

Finally, I raise the question of whether theories that will in fact not be complied with can be, as I have claimed, 'justifiable'. Or, does futility mean that there must be something wrong with these theories? I argue that, at least if we take moral realism for granted, futility and truth go together.

Now to the objections raised by my critics. I start by noting that I am extremely grateful for the interest they have shown in my book and for their astute comments on it. Here is how I respond to them. I discuss them in the order I have read them, which happens to be in alphabetical order (not the order in which they have been published).

\section{On Local Justice and Preference Satisfaction: A Response to Robert E. Goodin}

Since there is much in common between the positions of Goodin and myself, I have tried to tease out where we can find differences of opinion. Goodin notes that while I apply what he calls 'global' ethical theories to problems of the setting of priorities in health-care, there is no discussion in my book of principles of 'local' justice. This is a correct observation, and this is of course intentional. What is special about my book is precisely its attempt to apply global ethical theories to down-to-earth decisions about how to distribute scarce medical resources directly. This does not mean that I see no role in medicine to be played by local principles. In particular, they seem to play a role in political situations where decisions must be made. They can help people reach agreements and to find some sort of rationale behind their joint decisions. However, in the present context, there are two severe obstacles with such local principles. First of all, they are deliberately given a vague form in order to allow very different understandings of them. This is a problem when we are interested in a moral assessment of radical departures from actual practice. In particular, this is a problem if we seek a deep moral understanding through the moral explanation of these departures. Moreover, if these local principles are taken seriously, it is in no way easier to defend them with reference to global principles than it is to defend definite proposals as how best to redirect medical resources. The best way of defending one such 
principle would be to show that it has good consequences when people believe in it and use it in negotiations and rationalizations of actual medical decisions. This is no easy task. Or, one could try to derive them from some basic deontological principle. Again, this is no easy task. Moreover, if taken literally, these principles lead us in the wrong direction when difficult cases need to be settled. One such principle urges us never to abandon a patient. Goodin notes that "utilitarianism fails to account for non-abandonment of chronic-care patients when medical facilities are swamped by acute cases." But on one reading of the principle, it demands that patients should only be offered assisted death when it is not reasonable to treat them (considering the needs that are easier to meet from other patients). Then there is no conflict with utilitarianism. Nor is there any conflict with any reasonable basic deontological principle I can think of. However, the principle could require that the patient be treated before the doctor, even at the cost of other patients. If this is what it means to take the principle seriously, then the conflict with utilitarianism (and with any reasonable deontological principle) is real. But then we need to ask the following question: Under the circumstances, what is the doctor morally obliged to do? This question can only be answered satisfactorily with reference to a global principle. And it should not be handled at the bedside, but when standard practice is established.

Goodin discusses the possible explanations behind what I have called 'futility'. We are very much in agreement about these psychological explanations. Several of them also appear in my book. And we also agree to some extent that they may sometimes have something counting in defence of them. To mention the example I have given. I think it is a good idea to spend enormous resources when we want to save a few miners trapped in a pit, even if, for the same amount of money, we could have built a roundabout which would have statistically saved more lives in the future. It is a pity that we have such difficulties in sympathizing with merely statistical people (patients) but it is a good thing that we can at least sympathize with those we have in front of us. We should be careful not to undermine the ability we have to sympathize. However, in many cases, where money is spent on what I call 'marginal life extension', we actually harm the patients to whom we give priority (old people near the end of their lives, for example) while we forget the merely statistical patients suffering from mental illness who have to bear the opportunity costs. We could avoid this and yet cater to our willingness to sympathize with those in front of us if we adopted different forms of medical practice. We could avoid eroding our empathy if the doctor could say truthfully to these patients that there is no further cure available, only palliative care including assisted death. Yet we don't and this is indeed irrational. It is 'irrational' in most of the five senses between which I distinguish and yet this irrationality seems unavoidable.

If the doctor refuses to let her patient go, should the doctor's preference to this effect not count for something? It should, at least according to Goodin:

For welfare consequentialists such as Tännsjö and me, preference satisfaction is after all the coin of the realm. So the fact that physicians have those preferences must presumably count - not necessarily decisively, but nonetheless count - toward making them morally justifiable at least in the eyes of us welfare consequentialists. ${ }^{1}$

\footnotetext{
${ }^{1}$ Goodin (2020): 31.
} 
I disagree. As Goodin knows, I am a hedonist, not of preferentialist, but this is of little importance in the present case. Certainly, no preference utilitarian would count the satisfaction of just any preference as valuable in itself. Of importance are only intrinsic preferences. It is unlikely that the physician's preference to treat the patient before her eyes is intrinsic in nature. Moreover, it seems reasonable to only focus on self-regarding preferences (in order to avoid double-counting). ${ }^{2}$ And, most importantly in the present context, the preferences of the medical doctor, even if it should count for something, should count less than the preferences of all the affected patients. I think here of those before the eyes of the doctor, of course, but also the merely statistical patients who carry the opportunity costs when the doctor turns a blind eye to them.

\section{On the Best Way of Understanding Rawls and Contractualist thinking: An Answer to Quinn Hiroshi Gibson}

Gibson notes the similarity between the theory I call the Maximin/Leximin theory and Rawls' difference principle. He also notes that I do not intend to give an interpretation of Rawls but to put forward merely a similar (and better, i.e. a complete moral) theory based on what I consider to be the rationale behind Rawls' difference principle: the separateness (and integrity) of persons. Rawls concludes from this metaphysical principle that, even if compensation within lives is possible, compensation between lives is not. The loss made by one person cannot be compensated by any (larger) gain made by another person. To this is added the idea that we should act so as to render the worst-off individual as well off as possible. I take these claims seriously.

According to Gibson, there is more to Rawls' theory of justice than this. He also points out that the metaphysical rationale (the separateness and integrity of persons) underdetermines the idea that, even if compensation within lives is possible, it is not possible between lives. Nor does the idea that we should act so as to maximize well-being for the individual who is worst off follow strictly from the metaphysical rationale. These observations are correct. I discuss this in my book, and I point out that Robert Nozick seems to derive a different conclusion from the very same metaphysical rationale: interpersonal comparisons of well-being are impossible. From the idea that interpersonal comparisons are meaningless, Rawls' idea that we cannot compensate the loss of one person with a gain of another follows, of course, but his idea that we should make the worst-off individual as well off as possible does not. This claim is inconsistent with the idea that we cannot make interpersonal comparisons. And yet, any theory based on Rawls' argument presents us with an interesting theory, similar but not identical to Rawl's difference principle. I here operate with a (global) moral theory, Maximin/ Leximin, which I have designed to fit Rawls' rationale, and which I claim is defensible.

Many things Gibson has to say about Rawls' theory of justice and his 'derivation' of it are very interesting. His comparisons between my take on the theory and how G.A. Cohen understands it are informative. However, since I have deliberately focused on the idea I explicitly put forward, which is not intended to capture Rawls' intentions, most of what is said in Gibson's reply, for all its interest in its own right, is irrelevant for

${ }^{2}$ I address these questions in Tännsjö (1998), Chapter 6. 
my argument. However, what is of the outmost relevance is the author's claim that one can find a different theory of justice, which I have neglected, and which I should have discussed. Since I claim that the theories I focus on are the most interesting ones (even the only defensible ones), I need to come up with an answer to this objection.

First, however, a note on deontological constraints mentioned by Gibson. Rawls himself renders his principles of liberty lexically superior to his difference principle. Does this and other deontological constraints bode problems for my discussion? In my treatment of priority setting in health-care I have left it an open question of whether there are any deontological constraints that must be met. I have taken for granted that it is possible to find an efficient way of setting priorities without having resort to anything like the killing of innocents or the torture of children. However, when I offer assisted dying as a way of avoiding too much spending on futile marginal life extension, I discuss two possibilities. One is that euthanasia could be legalized, which would of course be helpful. Or, that for strict deontological reasons euthanasia remains forbidden, but I then argue that terminal sedation may serve as an ersatz and should be provided at request. Terminal sedation is not euthanasia in disguise. So standard deontological constraints pose no serious threat to the suggestions I make in the book. In the sequel, however, I will return to this problem.

However, what about the comments on (fair) procedures and contractualism made by my critic? Gibson urges us to "evaluate our healthcare priorities with respect to whether they are arrived at through procedures which are fair and which embody our commitments to the freedom and equality of all persons." 3

First of all, there is much focus on (fair) procedures in part two of the book, ranging from the flipping of coins to the introduction of Adjusted Clinical Groups. However, there is no discussion of any theory of distributive justice relying merely on procedures. The most famous example is, of course, that of Robert Nozick. A methodological advantage with his approach to justice is that he need not rely on interpersonal comparisons of well-being. However, I have rejected his view elsewhere for moral reasons. ${ }^{4}$ I do not think it is wise to focus on procedures instead of looking at moral principles advising us what to do and why we should do it. In order to assess if a procedure is appropriate or not, we need to look at the distributive patterns it engenders and supports.

But what about contractualism? Have I not missed out on the possibility of treating Rawls as a contractualist? What about Gibson's claim that Rawls "highlights the key Contractualist idea that social arrangements need to be justifiable to each"? Should I not have discussed this and are there not many other contractualist approaches I should have included when I speak of justifiable basic moral theories? I think not.

There are roughly two ways of understanding contractual thinking. One kind of contractual thinking takes place against the backdrop of moral nihilism, or at least the idea that people won't take any notice of morality anyway. So we need to find ways of living together peacefully without having recourse to moral thinking. We need to negotiate in the search of reasonable principles of co-operation. And, given that one individual is much stronger than another, it may turn out to be reasonable for both to

\footnotetext{
${ }^{3}$ Gibson (2021): 15.

${ }^{4}$ Tännsjö (2015).
} 
agree that the latter be a slave of the former. ${ }^{5}$ This is a fascinating topic, but it is irrelevant to my purposes. My interest is in applying (global) ethical theories to see what they tell us about how best to allocate resources for health-care purposes. Does this mean that I presuppose moral realism? Or, could an ethical theory provide ethical explanations without any claim to providing the absolute truth, let alone reaching it, independently of our conceptualizations? ${ }^{6}$ This is a deep and interesting question, yet alas one beyond the scope of the present discussion.

Another take on contractualism is to see it as presenting heuristic devices in our search for plausible ethical theories. This is the most straightforward way of understanding Rawls. But then, what is of interest in the present context are the theories that come out as the result of the hypothetical contract or abstract thought experiment. Only principles close to Rawls' difference principle (Maximin/Leximin) can both guide our decisions when we set priorities and morally explain why we should make them. My interest, at least in this book, is precisely in finding what such principles tell us to do and why we should do it. Hence the subtitle of my book: What Ethical Theories Tell Us.

Incidentally, this also answers a critical comment made by a reviewer in a different context. ${ }^{7}$ This is what Anders Herlitz has to say about my putative neglect of contractarian ideas:

For example, he could there have found the idea that an action is wrong if and only if it is impermissible according to a principle that no one can reasonably reject in conjuncture with the "minimax complaints model" of what grounds a reasonable rejection, which says: [An] individual can reasonably reject a principle if her level of well-being and burden, given widespread acceptance of the principle over her lifetime, combine into a complaint greater than that had by anyone else about some alternative principle, given widespread acceptance of that alternative over a lifetime. ${ }^{8}$

One could have added Thomas Scanlon to the list of contractarian thinkers here that I might have discussed; I think here of his idea that "thinking about right and wrong is, at the most basic level, thinking about what could be justified to others on grounds that they, if appropriately motivated, could not reasonably reject." ${ }^{\prime 9}$

If suggestions such as these are seen as providing heuristic devices, helping us in our search of the moral truth, then they are relevant to my purposes. However, what is of interest are not the devices as such but what principles surface when we employ them. Does any principle satisfy the requirements they make at all? Do several principles satisfy them? As they are all theoretically defensible, do the principles I discuss pass the test?

The tests, both Reibetanz' and Scanlon's, are too vague to admit any definitive answer to these questions. Remember also the different opinions between Harsanyi and Rawls about what would be contracted for by egoistically oriented but mutually

\footnotetext{
${ }^{5}$ See Gauthier (1986) for an indication of this and, for an even more cynical approach, Buchanan (1975).

${ }^{6}$ I thank a reviewer for the journal for having pressed this point.

${ }^{7}$ Herlitz (2020).

${ }^{8}$ Reibetanz (1998): 300.

${ }^{9}$ Scanlon (1998): 5.
} 
disinterested people who are put behind a veil of ignorance. Yet regardless of the outcome of the application of the tests, given moral realism, at most one of the conflicting theories passing the test can be true. We still need, once we believe we have seen our favored theory survive the heuristics, to express it clearly. Furthermore, we need to put it to crucial tests in abstract thought experiments. In particular, we need to do so in relation to problems in population ethics. Contractarian approaches are ill-designed to deal with such problems. Hence, I conjecture that once again we will meet with my three favored approaches.

\section{On Deontological Constraints. An Answer to Lasse Nielsen}

According to Nielsen, deontological constraints can play a role in rationalizing actual medical practice. In particular, the extreme focus on marginal life extension I have diagnosed as irrational, may gain support from deontological thinking. First a small note on Kant, however. "Human dignity in this Kantian sense implies that all humans are owed respect qua being human persons and that this implies that there are certain ways we will not allow that they are treated."10 I am not sure that this is a correct account of Kant. His interest is not, in the final analysis, in dignity as a property of human beings, but as a property of rational beings ${ }^{11}$ and hence he has no problem with abortion. ${ }^{12}$ Yet, the problem still needs to be addressed. Could we find a deontological rationale behind the neglect of merely statistical patients suffering from mental illness when we invest enormous resources in marginal life extension? Or, could we find a deontological rationale for withholding the resources now spent on marginal life extension? I think we can, but here we need to rely on procedures and practice. The trick is to invest fewer resources in certain types of treatment, and then to direct the resources to care and cure mental illness. This means that when an elderly patient's life could perhaps be extended somewhat if she undergoes a certain medical procedure, the patient is told that she is not eligible for the intervention. The odds are poor, the intervention may kill her, or cause her unnecessary suffering, the resources are scarce, and other patients with better odds need this cure. This does not mean that she is abandoned, however. She is provided with the best possible palliative care, including terminal sedation and (if this is a legal possibility) euthanasia. The scarce resources available for the kind of intervention she asks for go to people with a better prognosis.

I can't see why a deontologist defending human dignity would object to this. Furthermore, this person should have a special concern for mentally ill persons, who now tend to drop off the radar of many thinkers. They also possess dignity, deserve to be seen and their needs should be catered for.

But perhaps there are other examples. Nielsen points to orphan drugs. Some people suffer from extremely rare diseases where some treatment is available but at a very high cost. Instead, we can use the available resources to cure more mundane diseases and get more bang for our buck, as it were. Does such a setting of priorities

\footnotetext{
${ }^{10}$ Nielsen (2021): 37.

${ }^{11}$ I discuss this in Tännsjö (2015). See also Maninen (2014) for a similar point.

12 I discuss this at length in Tännsjö (2015).
} 
violate deontological constraints? Well, it is of note that this is how the matter is actually solved when decisions are reached as to how drugs should be introduced in a publicly financed system. In individual cases this is sometimes met with media hype and strong feelings. And yet, this is how the matter is treated and I think for good reasons, not only consequentialist ones. It also has to do with the fact that it is difficult to come up with a deontological principle forbidding such an allocation of resources. And this has little to do with human dignity. The idea that each individual should be given an equal chance of having her life extended (Taurek's idea) has absurd consequences and I discuss this in my book. ${ }^{13}$ The principle I advocate, that everyone should be given an equal maximal chance, is much more plausible. And if we must make a choice behind a veil of ignorance, I submit that we should opt for a maximal equal chance. This means that the resources go to the many rather than to the few.

Nielsen also adds to the discussion of the relative merits of a pure form of utilitarianism and utilitarianism with a prioritarian amendment. I am neutral towards them in the book, but I also confess where my sympathies lie (with utilitarianism). I agree that I have no knock-down argument in support of utilitarianism as compared to prioritarianism. The argument I present has a strong intuitive appeal on me, but I realise that not everyone thinks in the same manner. Some may think that a life with a net surplus of happiness may yet be not worth living, beause the downs in this life count heavier, from a moral point of view, than the ups.

Nielsen also tries to shed more light on a discussion between Shlomi Segall and myself about this. Nielsen is correct in his understanding of my view. If I understand him correctly, there exists also a different kind of prioritarianism which focuses only on increments and losses of happiness, with no idea about any absolute zero level. This restricted understanding of prioritarianism may be what Segall is after and he may have misunderstood my position in his objection. So, what are we to say about his alternative view? Well, to give up on the zero level is a high price to pay for a moral theory. Such a theory cannot answer Hamlet's question: To be or not to be? It cannot answer the question of when a life is worth living or not.

It is indeed an intricate methdological matter how to fix the zero level. I say a lot in the book about how to measure happiness, both intrapersonally and interpersonally, but I have little to say about the zero level. I merely note that, phenomenologically speaking, we can realize whether we are above or below a level where life is (prudentially) worth living.

Why don't I say more about this? I don't know what more to say!

\section{On a Special Form of Sufficientarian Thinking. An Answer to Jay A. Zameska}

Zameska joins those who think I have neglected one important theory when I examine what ethical theories tell us about priority setting in health-care. His concern is not with contractarian thinking, but with a special sufficientarian alternative (to the form of sufficientarianism which I do discuss). My answer to him will be in line with my answer to those who think I could have taken contractarian thinking more seriously: the theory

13 Tännsjö (2019): 40-42. 
he advocates does not present us with any additional defensible position (in the way 'standard' sufficientarianism does).

Zameska and I agree on one important (and controversial) point. A serious contender as a basic moral theory should be able to handle problems in population ethics. Such problems should not be 'quarantined', to use Parfit's phrase. ${ }^{14}$ But while all the theories I discuss fair reasonably well when applied to problems in population ethics, Zameska's theory fails completely, or so it seems to me.

The point of departure of Zameska's argument is a rejection of the idea that the theories $I$ discuss present us with defensible moral views. The problem with them, he claims, is that they all allow what Derek Parfit has nicknamed "the repugnant conclusion". A huge population with individuals living lives that are just worth living, assessed from a prudential point of view, the $\mathrm{Z}$ world, is preferable to a world of ten billion extremely happy people, the A world. This conclusion is implied by utilitarianism, with or without the prioritarian (and sufficientarian) amendment discussed by me. And it is at least, according to my diagnosis, allowed by the Maximin/Leximin theory as well as by standard egalitarian thinking.

Now, I happen to be quite satisfied with this repugnant conclusion. I have argued in defense of the claim that we should accept it for at least 30 years. In the early days I felt somewhat alone in my acceptance of it, but it seems now that the tide has turned. For a recent defense of the claim that one should not reject a moral theory because it implies a repugnant conclusion, see a recent article. ${ }^{15}$ In the present context, I will not repeat myself.

What then about Zameska's complicated sufficientarian theory, which elaborates on a suggestion made by Harry Frankfurt in the mid-1980s, and which is clearly different from the one I have discussed, which is rather inspired by ideas put forward much more recently by Roger Crisp? ${ }^{16}$ Does it avoid the repugnant conclusion? This is far from obvious. In order to avoid the repugnant conclusion, he labors with a critical level, a threshold where a life worth living (from a prudential point of view) turns into a life 'good enough', assessed from the point of view of his sufficientarian theory. Lives below this threshold, even if they are worth living from a prudential point of view, possess negative moral value. But he doesn't tell us exactly where this critical line should be drawn: "I won't address how exactly to set the threshold here", he writes.

This means that he is open to the following dilemma. If he keeps the critical level low, very near the level where a life prudentially speaking starts to be worth living, he will have to acknowledge something very close to the repugnant conclusion. He will have to accept that a world very similar to the $\mathrm{Z}$ world is better than the A world. So let us suppose that he wants to stay clear of this outcome by arguing that there is a considerable difference between the two levels, the one where life starts to be worth living (prudentially speaking) and where it is good enough, assessed from his favored setting of the critical sufficientarian threshold, to count for something positive in the moral calculus. But it brings us to the other horn of his dilemma. He is now open to an objection

\footnotetext{
14 Parfit (2004): 257.

15 Zuber et al. (2021).

16 Crisp (2003).
} 
to his theory with which he is familiar. It now seems that an empty world is better than a world with a huge population living close to but under the sufficientarian level of a life that is good enough in order to count positively in the moral calculus, but considerably better than a life just worth living. ${ }^{17}$

Zameska is willing to bite this bullet: "I don't find this objectionable at all - particularly when we consider that although maximizing theories avoid this objection, they entail the repugnant conclusion." ${ }^{18}$ I disagree. When I contemplate it, I find the conclusion that the empty world is better than a world with people happy to be around, even if not happy enough to satisfy the sufficientarian requirement, very sad. And since I see no reason to avoid the repugnant conclusion, I lack Zameska's grounds for being complacent with respect to it. But it is possible to strengthen the objection in a manner that makes it irresistible. It is not only that an empty world is better than a huge world of happy individuals (living below the critical level), it is also the case that a world with a few people suffering terribly would be preferable to a world with a huge number of quite happy (just below the sufficientarian level) individuals. Here clause 1 in Zameska's theory kicks in. The number of people below the threshold is fewer in the world with a few people suffering terribly than in the world where many people are happy to be around (even if they have not reached to sufficientarian level). Any reference to a critical level below which lives detract from moral value is open to this objection, which has been nicknamed by Gustaf Arrhenius (there are many nicknames in this discussion) "the sadistic conclusion" ${ }^{19}$ As soon as we want to "minimize the disvalue associated with below threshold lives", as Zameska puts it, we are open to this objection.

If I am right about this, it would not have been a good idea to include Zameska's complicated sufficientarian theory among the theories I examine. Yet, it might be of interest to ponder a question he never raises. Had I included his theory among defensible moral theories, would it too have pointed in the same direction that I claim that the other theories do: away from marginal life extension to more investment in the care and cure of people suffering from mental illness?

I am not sure about this. It seems to me that at the present state of our knowledge about mental illness, and the cures and treatments presently available, it is highly likely that there are many patients whom we can help to lives worth living, if enough resources are used to this purpose, but not to lives good enough when assessed from the sufficientarian point of view. And the higher - in order to stay clear of the repugnant conclusion - the sufficientarian threshold for when a life is good enough is set, the more pronounced the difference in this regard will be between this theory and the theories I have considered defensible. In contrast, there are bound to be many patients with slight discomforts whom we could lift above the critical level if we invested instead in them.

Had I included Zameska's favored theory there would have been no such thing as convergence.

\footnotetext{
17 Casal (2007).

18 Zameska (2021): 50, f.n. 15.

19 Arrhenius (2000).
} 


\section{Conclusion}

I have stood my ground in a hardnosed manner in my answers to my critics. This is as it should be. I have not been convinced that I am wrong in any of my fundamental claims in my book. When there is disagreement, it should be rendered visible and be possible for a reader to critically assess it. I hope my critics and I have accomplished this jointly. However, it has surfaced that many of my points made in the book need clarification. I thank my critics for having pointed this out and helped me to the best of my knowledge to provide it. In particular, it has been helpful to get a chance to explain my somewhat idiosyncratic but seriously held view on contractual moral thinking. There are, of course, many remaining points to discuss in my book, in particular concerning the empirical assumptions made in it; this must wait for another occasion, however, when the book is scrutinized not only by philosophers but by economists and medical doctors as well.

\section{References}

Arrhenius G. (2000), “An Impossibility Theorem for Welfarist Axiology,” Economics and Philosophy 16 (2): 247-266.

Buchanan J.M. (1975), The Limits of Liberty: Between Anarchy and Leviathan, University of Chicago Press, Chicago.

Casal P. (2007), "Why Sufficiency Is Not Enough," Ethics 117 (2): 296-327.

Crisp R. (2003), “Equality, priority, and compassion,” Ethics 113 (4): 745-763.

Gauthier D. (1986), Morals By Agreement, Oxford University Press, Oxford.

Gibson Q. H. (2020), "Rawlsian Contractualism and Healthcare Allocation: A Response to Torbjörn Tännsjö," Diametros 18 (68): 9-23.

Goodin R. E. (2020), “Setting Health-Care Priorities: A Reply to Tännsjö,” Diametros 18 (68): 24-32.

Herlitz A. (2020), “Review of Torbjörn Tännsjö, Setting Health-Care Priorities," Economics and Philosophy 36 (3): 460-465.

Manninen B. A. (2014), “A Kantian Defense of Abortion Rights with Respect for Intrauterine Life," Diametros 39: 70-92.

Nielsen L. (2021), “Defending Deontic Constraints and Prioritarianism: Two Remarks on Tännsjö's Setting Health-Care Priorities," Diametros 18 (68): 33-45.

Parfit, D. (2004) "Postscript," [in:] The Repugnant Conclusion. Essays on Population Ethics, J. Ryberg and T. Tännsjö (eds.), Kluwer, Dordrecht: 257.

Scanlon T.M. (1998), What We Owe to Each Other, Harvard University Press, Cambridge (MA)/ London.

Tännsjö T. (1998), Hedonistic Utilitarianism. A Defence, Edinburgh University Press, Edinburgh.

Tännsjö T. (2015), Taking Life. Three Theories on the Ethics of Killing, Oxford University Press, New York/Oxford.

Tännsjö T. (2019), Setting Health-Care Priorities. What Ethical Theories Tell Us, Oxford University Press, Oxford.

Zameska J. (2020), “The Suffi cientarian Alternative: A Commentary on Setting Health-Care Priorities," Diametros 18 (68): 46-59.

Zuber S. et al. (2021), "What Should We Agree on about the Repugnant Conclusion," Utilitas, published online: 13 April 2021 doi:10.1017/S095382082100011X. 